\title{
Uneventful spinal anesthesia for a patient with carcinoid syndrome managed with long-acting octreotide
}

\author{
[Une rachianesthésie sans incident réalisée avec l'octréotide à action prolongée \\ chez un patient atteint d'un syndrome carcinoïde]
}

Sharon Orbach-Zinger MD, ${ }^{*}$ Raphael Lombroso MD, $†$ Leonid A. Eidelman MD*

Purpose: To present a case of spinal anesthesia in a patient suffering from carcinoid syndrome undergoing an inguinal hernia repair. In the past, regional anesthesia was considered unacceptable in these patients because of the possibility of intraoperative hypotension, hypertension, or bronchospasm. Recently, however, the preoperative use of octreotide, the synthetic analogue of the naturally occurring hormone somastatin, has been found to prevent these complications. Nevertheless, it remains unclear whether the use of this drug in patients with carcinoid syndrome allows the possibility of regional anesthesia.

Clinical findings: We report the uneventful use of spinal anesthesia in a patient suffering from carcinoid syndrome treated with longacting octreotide. With careful attention to volume status of the patient and low volume of local anesthetics ( 10 mg hyperbaric bupivacaine $0.5 \%$ ) supplemented with intrathecal narcotics (fentanyl 20 $\mu \mathrm{g})$, we were able to prevent any episodes of intraoperative hypotension in this patient. Octreotide was available in the operating theatre in case of an emergency. One of the original aspects of this case report is that the patient received long-acting octreotide (once a month administration) instead of the usual daily dose. In addition this is one of the few reports of spinal anesthesia administered to a patient with carcinoid syndrome.

Conclusion: Preoperative octreotide may result in more favourable conditions for regional anesthesia in patients with carcinoid syndrome. However, further studies will be required to confirm the favourable outcome observed in this patient.

Objectif : Présenter un cas de rachianesthésie chez un patient, atteint d'un syndrome carcinoïde, qui devait subir une herniorraphie inguinale. Dans le passé, on considérait l'anesthésie régionale comme inacceptable chez ce type de patient, étant donné la possibilité d'hypotension peropératoire, d'hypertension ou de bronchospasme.
Récemment, toutefois, l'usage préopératoire d'octréotide, analogue synthétique de la somastatine naturelle, a montré qu'il prévient ces complications. Néanmoins, on ne sait pas encore avec certitude si l'emploi de ce médicament chez des patients atteints de carcinoïde permet d'utiliser une anesthésie régionale.

Constatations principales: Un examen consciencieux de l'état volumique du patient et l'administration d'un faible volume d'anesthésiques locaux ( $10 \mathrm{mg}$ de bupivacaïne hyperbare à 0,5\%) complétés par un narcotique intrathécal (20 $\mu \mathrm{g}$ de fentanyl), ont permis de prévenir tout épisode d'hypotension peropératoire. L'octréotide était disponible en salle d'opération en cas d'urgence. L'originalité de cette présentation de cas est que le patient a reçu de l'octréotide à action prolongée une fois par mois plutôt que la dose quotidienne habituelle. C'est aussi l'un des rares articles sur la rachianesthésie administrée à un patient atteint d'un syndrome carcinoïde.

Conclusion : L'octréotide préopératoire peut améliorer les conditions de l'anesthésie régionale chez des patients atteints d'un syndrome carcinoïde. Cependant, d'autres études devront confirmer l'évolution positive observée chez ce patient.

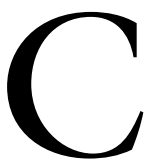

ARCINOID tumours are the most common of the gastrointestinal endocrine tumours. They arise from neuroendocrine cells, can be found anywhere in the body, but are most commonly found in the gastrointestinal tract, liver, pancreas and pulmonary bronchi. Approximately $5 \%$ of patients exhibit symptoms of carcinoid syndrome, mainly those with liver involvement or with carcinoid tumours outside the gastrointestinal tract. ${ }^{1}$ This syndrome is characterized by a myriad of

From the Departments of Anesthesiology, ${ }^{*}$ and Surgery A†, Rabin Medical Center, Beilinson Campus, Petach Tikva, Israel. Address correspondence to: Dr. L.A. Eidelman, Department of Anesthesiology, Rabin Medical Center- Beilinson campus, Petach Tikva

49100, Israel, Phone: 972-3-937-6850; Fax: 972-3-937-6851; E-mail: leidelman@clalit.org.il Accepted for publication January 8, 2002.

Revision accepted March 28, 2002. 
manifestations including cutaneous flushing, diarrhea, valvular disease, bronchospasm and hemodynamic disturbances. Patients displaying these symptoms present a challenge to the anesthesiologist since intraoperative hyper or hypotension and bronchospasm are not uncommon. ${ }^{1}$ Regional anesthesia is considered contraindicated in these patients because of the resulting sympathectomy. ${ }^{2}$ However a case report was published detailing successful outcome using epidural anesthesia in a patient with carcinoid syndrome undergoing transurethral resection of the prostate. ${ }^{3} \mathrm{We}$ report the case of a patient receiving the long-acting formulation of octreotide for treatment of carcinoid syndrome who underwent inguinal hernia repair under spinal anesthesia.

\section{Case report}

A 66-yr-old male was admitted to the surgery ward for inguinal hernia repair. Because of the large size of the inguinal hernia, local anesthesia was deemed impossible. He was diagnosed as having a carcinoid tumour in the liver 13 years earlier. At that time, he presented to the hospital with complaints of weight loss and facial flushing. Upon questioning, the patient also revealed frequent bouts of diarrhea. Carcinoid syndrome was diagnosed on the basis of an elevated urinary 5hydroxyindole acetic acid levels (5-HIAA). A computerized tomography scan of the liver revealed multiple liver masses whereas colonoscopy revealed a benign polyp. The patient visited the endocrinology clinic only sporadically for the next ten years. In 1997, the patient's treatment regimen was switched from regular daily octreotide to slow release octreotide $30 \mathrm{mg}$ (Sandostatin LAR, Novarth Basal) once a month, in order to ensure better patient compliance. In 1998, however, he reappeared with complaints of nocturia and pitting leg edema. Echocardiography at that time revealed a dilated right atrium and ventricle with severe tricuspid regurgitation and right ventricular dysfunction.

At the time of present hospital admission the patient still complained of leg edema and nocturia but denied episodes of flushing and diarrhea. In addition he suffered from paroxysmal atrial fibrillation. He was treated with furosemide, coumadin, atenolol, digoxin and spironolactone in addition to octreotide.

On admission, physical examination revealed a blood pressure of $122 / 76$, pulse 56 beats. $\mathrm{min}^{-1}$, and a respiratory rate of 12 breaths $\mathrm{min}^{-1}$. Physical findings were remarkable only for abdominal ascites. Electrocardiogram (EKG) revealed atrial fibrillation with a slow ventricular response and right bundle branch block. Chest $x$-ray revealed an enlarged heart and an obscured left costophrenic sinus. Transthoracic echocardiography revealed no significant changes from the examination performed three years earlier, i.e., a dilated right atrium and ventricle with severe tricuspid regurgitation and right ventricular dysfunction. Blood tests revealed an international normalized ratio of 3.13 attributed to coumadin therapy.

On admission, the coumadin was replaced with iv heparin. Because of a technical delay in the commencement of surgery, the patient did not receive heparin for $16 \mathrm{hr}$ before surgery and his coagulation study was normal. The patient received his usual medication prior to surgery. The patient had received the last dose of octreotide four days prior to surgery. $\mathrm{He}$ was given midazolam $5 \mathrm{mg}$ orally as premedication.

In the operating room, the patient was given $1 \mathrm{mg}$ of $i v$ midazolam. In addition, he received a bolus of 300 $\mathrm{mL}$ Ringer's lactate preoperatively. Monitoring included 5 lead EKG, pulse oximetry, and invasive arterial blood pressure. Oxygen was delivered via facial mask. Octreotide was prepared in case of an intraoperative crisis. The patient was seated and a $22 / 27 \mathrm{~g}$ Polymedic ${ }^{\circledR}$ (SARL, France) conical elliptical needle was introduced into the L4-L5 spinal space. The patient received 10 mg heavy bupivacaine $0.5 \%$ (hyperbaric; Astra, Sweden) and $20 \mu \mathrm{g}$ fentanyl subarachnoidally. The patient was placed in a reverse Trendelenburg position to prevent too high a level of spinal anesthesia. After waiting seven minutes, we determined the patient's sensory level by cold discrimination test. A sensory block of T6 was obtained and surgery commenced, lasting approximately $90 \mathrm{~min}$. During surgery the patient remained hemodynamically stable with blood pressures ranging from $105 / 55-143 / 78 \mathrm{mmHg}$. No important bleeding was encountered. Pulse oximetry remained normal throughout the procedure. An additional $700 \mathrm{~mL}$ of Ringer's lactate was infused during the operation. No vasopressors or inotropes were necessary.

Postoperatively, the patient was monitored overnight in the recovery room. His postoperative course was uneventful and the patient was discharged home three days later. The patient's medications were resumed the day following surgery.

\section{Discussion}

Initially it was believed that the symptomatology of carcinoid syndrome was attributable only to tumour release of serotonin and histamine. ${ }^{4}$ More recently, however, it was shown that these tumours release multiple hormones and mediators including tachykinins, bradykinins, prostaglandins, adrenocorticotropic hormone, vasoactive intestinal peptide, substance $P$, dopamine and neurotensin. ${ }^{2,5-7}$ 
Preanesthetic management of carcinoid syndrome involves blocking these mediators. Treatment regimens have included $\mathrm{H} 1$ and $\mathrm{H} 2$ blockers, cyproheptadine, ketanserin, octreotide (the synthetic analogue of somastatin), aprotinin or a combination of the above. ${ }^{8}$ More recent studies have been inconclusive on the effectiveness of prophylactic treatment with cyproheptadine, kentanserin, and aprotinin ${ }^{9-12}$ and have recommended pretreatment with octreotide and histamine blockers only. $9,13-15$ Octreotide exerts pharmacologic actions similar to the natural hormone, somastatin. It is a potent inhibitor of growth hormone, glucagons, and insulin. Like somastatin, it also suppresses luteinizing hormone response to gonadotropin releaving hormone, decreases splanchnic blood flow, and inhibits release of serotonin, gastrin, vasoactive peptide, secretin, motilin, and pancreatic polypeptide. Because of these pharmacological actions, octreotide has been used to treat the symptoms of metastatic carcinoid tumours and vasoactive intestinal peptide secreting adenoma. We omitted the use of histamine blockers since histamine release is found mostly in gastric carcinoid tumours. ${ }^{16}$ Octreotide in a dose of $100 \mu \mathrm{g}$ three times daily for three weeks prior to surgery has been recommended $;^{3}$ we believed this treatment to be redundant since the patient had received a long-acting dose four days earlier. Nevertheless octreotide was ready in the surgical suite in the case of an intraoperative complication.

Most patients with carcinoid syndrome have been anesthetized with general anesthesia. Regional anesthesia is usually considered inappropriate for these patients because of the resulting sympathectomy. Whereas the use of epidural anesthesia in a patient with carcinoid syndrome has been reported, even those authors believed spinal anesthesia to be contraindicated because of its more pronounced effect on sympathetic innervation. ${ }^{3}$ In our case, regional anesthesia was chosen because of the patient's preference. In addition, we believed that general anesthesia with positive pressure ventilation could be detrimental for the patient because of its influence on venous return, compromising right ventricular filling, an important limitation in the presence of severe tricuspid regurgitation. $^{22}$ We chose spinal anesthesia over epidural anesthesia because of the decreased risk of epidural hematoma formation in a patient who had received anticoagulant therapy. Furthermore, we felt that spinal anesthesia would provide better surgical relaxation, an important consideration in this patient with increased abdominal pressure because of ascites.

Stevens $e t a l$. found no increased attenuation of the sympathetic response by spinal when compared to epidural anesthesia. ${ }^{18}$ We feel that we prevented an intraoperative hypotensive crisis by the preoperative administration of octreotide, by the administration of adequate fluids, and by the use of a relative low dose of spinal local anesthetic supplemented with intradural opiates. Octreotide has been shown to be effective both in prophylaxis and treatment of intraoperative hypotension and bronchospasm. ${ }^{13-15}$ Adequate intraoperative fluids are necessary to correct hypovolemia that may be present especially in patients with diarrhea-induced fluid and electrolyte losses. ${ }^{19}$ Finally, moderate doses of intraspinal local anesthetic combined with opiates minimize sympathectomy and prevent blocking of the cardiac accelerator fibres.

Regional anesthesia was well tolerated in this patient with carcinoid syndrome. However, it is our impression that it is important to manage these patients adequately with preoperative octreotide.

Long-acting octreotide was used instead of regular octreotide in the intraoperative setting. After the first injection, octreotide levels rise sharply but fall subsequently reaching a nadir at about seven days. Afterwards they rise slowly, reaching a plateau at 14 days and remain elevated for the entire month. After subsequent injections, there is no nadir but rather adequate coverage for the entire month. This distinction is clinically relevant and suggests that a patient receiving long-acting octreotide for the first time should have surgery delayed until two weeks after the injection, unless regular octreotide is given as a supplement. This precaution is not necessary in patients on chronic treatment. Our patient had received the longacting formulation for a year prior to surgery and therefore we felt that additional octreotide was not needed in the preoperative period.

In conclusion we present the successful use of spinal anesthesia in a patient with carcinoid syndrome controlled with long-acting octreotide, a synthetic analogue of somastatin.

\section{Acknowledgement}

We would like to thank Dr. Benjamin Glazer, the patient's attending endocrinologist, for his help in reviewing this article.

\section{References}

1 Kaplan L. Endocrine tumours of the gastrointestinal tract and pancreas. In: Isselbacher KJ, Braunwald E, Wilson JD, et al. (Eds.). Harrison's Principles of Internal Medicine. New York: McGraw-Hill Inc., 1994: 1537-9.

2 Vaughan DJA, Brunner MD. Anesthesia for patients with carcinoid syndrome. Int Anesthesiol Clin 1997: 35: 129-42. 
3 Monteith K, Roaseg OP. Epidural anaesthesia for transurethral resection of the prostate in a patient with carcinoid syndrome. Can J Anaesth 1990; 37: 349-52.

4 Pernow B, Wadenstrom J. Paroxysmal flushing and other symptoms caused by 5 -hydroxytryptamine and histamine in patients with malignant tumors. Lancet 1954; ii: 951.

5 Eriksson B, Öberg $K$. Peptide hormones as tumor markers in neuroendocrine gastrointestinal tumors. Acta Oncol 1991; 30: 477-83.

6 Oates JA. The carcinoid syndrome. N Engl J Med 1986; 315: 702-4.

7 Breivik $H$. Perianaesthetic management of patients with endocrine disease. Acta Anaesthesiol Scand 1996; 40: 1004-15.

8 Veall GRQ Peacock JE, Bax NDS, Reilly CS. Review of the anaesthetic management of 21 patients undergoing laparotomy for carcinoid syndrome. Br J Anaesth 1994; 72: 335-41.

9 Watson JT, Badner NH, Ali MJ. The prophylactic use of octreotide in a patient with ovarian carcinoid and valvular heart disease. Can J Anaesth 1990; 37: 798-800.

10 Marsh HM, Martin JK Jr, Kvols LK, et al. Carcinoid crisis during anesthesia: successful treatment with a somatostatin analogue. Anesthesiology 1987; 66: 89-91.

11 Kvols LK, Martin JK, Marsch HM, Moerte CG. Rapid reversal of carcinoid crisis with a somatostatin analogue (Letter). N Engl J Med 1985; 313: 1229-30.

12 Castheley PA, Jablons M, Griepp RB, Ergin MA, Goodman K. Ketanserin in the preoperative and intraoperative management of a patient with carcinoid tumor undergoing tricuspid valve replacement. Anesth Analg 1986; 65: 809-11.

13 McCrirrick A, Hickman J. Octreotide for carcinoid syndrome (Letter). Can J Anaesth 1991; 38: 539-40.

14 Pratila $M G$. Propofol infusion in carcinoid syndrome (Letter). Can J Anaesth 1991; 38: 943-4.

15 Quinlivan JK, Roberts WA. Intraoperative octreotide for refractory carcinoid-induced bronchospasm. Anesth Analg 1994; 78: 400-2.

16 Roberts LJ 2nd, Bloomgarden ZT, Marney SR Jr, Rabin $D$, Oates $J A$. Histamine release from a gastric carcinoid: provocation by pentagastrin and inhibition by somatostatin. Gastroenterology 1983; 84: 272-5.

17 Stoelting RK, Dierdorf SF. Diseases of the gastrointestinal system. In: Stoelting RK, Dierdorf SF (Eds.). Anesthesia and Co-existing Disease, $3^{\text {rd }}$ ed. New York: Churchill Livingstone Inc., 1993: 283-4.

18 Stevens RA, Beardsley D, White JL, Kao TC, Gantt R, Holman $S$. Does spinal anesthesia result in a more complete sympathetic block than that from epidural anesthesia? Anesthesiology 1995; 82: 877-83.
19 Dougherty TB, Cronau LH Jr. Anesthetic implications for surgical patients with endocrine tumors. Int Anesthesiol Clin 1998; 36: 31-44. 